\title{
Smart Tightening Development for Aeronautical Bolted Assemblies in an Industry 4.0
}

\author{
Charly Foissac ${ }^{1(凶)}$, Alain Daidie ${ }^{1}$, Stephane Segonds ${ }^{1}$, and Clément Chirol ${ }^{1,2}$ \\ ${ }^{1}$ Université de Toulouse, Institut Clément Ader, UMR CNRS 5312, INSA/UPS/ISAE/Mines, \\ Toulouse, France \\ charly.foissac@insa-toulouse.fr \\ 2 Airbus Operations S.A.S., Toulouse, France
}

\begin{abstract}
Smart tightening development is part of the Industry 4.0 transformation with the introduction of smart tools, and preload in bolted assemblies is of major interest in today's aircraft manufacturing process. So far, it has been difficult to estimate the importance of each parameter for tightening process quality, mainly because of the large number of combinations and configurations that exist.

The present work aims at evaluating the effects and the interactions between different parameters that have to be taken in consideration in future torquing strategy. Many experimental tests have been conducted on an Automatica test bench using a Taguchi strategy and an analysis of the first main results is now presented, highlighting the complexity of the phenomena studied.

All these points will help us to better understand tightening, so as to improve performance during installation, maintenance and repair.
\end{abstract}

Keywords: Smart tightening $\cdot$ Design of experiments $\cdot$ Taguchi $\cdot$ Bolted assemblies

\section{Introduction}

With millions of fasteners needed to complete the A350, the challenge of mastering the tightening of bolted connections cannot be overlooked.

The aim of this research work was to develop a predictive tool to better control tightening behaviour through the torque/tension relationship, integrating strongly non-linear local phenomena. Controlling the preload within the bolted assembly can be beneficial for the integrity of the aircraft $[1,2]$ but this tool developed for an industry 4.0 which is geolocated and able to feed a dynamic database can also be an advantage for quality control and maintenance [3]. However, the preload is a very dispersive variable [4] and is difficult to control in production with current clamping tools [5]. One of the objectives is to optimize the tightening instructions that meet aeronautical requirements, in an uncertain environment [6]. This initiative should minimize the cases of over-torque and under-torque and lead to an assessment of the risks implied for the tightening efficiency. It should also provide an understanding of the mechanical behaviour of fastening elements impacted by faults. However, if we consider all the parameters of a bolted connection, 
we obtain a total of approximately 7,050 combinations per diameter. Table 1 lists the number of possible parameter solutions, without taking compatibility into account, when we use a bolted assembly.

Table 1. Number of solutions for each parameter.

\begin{tabular}{l|l|l|l|l|l}
\hline Fastener & Technology & Material & Surface finish & Lubrication & Diameter \\
\hline Bolt & 64 & 4 & 6 & 4 & 26 \\
\cline { 1 - 3 } Nut & 65 & 5 & 7 & 6 & \\
\hline
\end{tabular}

Given the large number of possible combinations, the behaviour of bolted connections can only be understood by creating a large database, in particular using design of experiments (DOE). Many research works have aimed to develop methods of constructing designs of experiments that make it possible to obtain a maximum of information with a minimum of known points, whilst remaining robust with respect to random and approximation errors [7]. These include:

- Mixed level DOEs, with as many factors as desired, each factor taking the number of levels necessary for proper execution of the study;

- Box-Behnken DOEs [8], which respect the rotational isovariance criterion;

- Rechtschaffner DOEs [9], simplified fractional DOEs which allow the effects of factors and second order interactions to be determined;

- Taguchi DOEs, based on the most famous theory for quality, which allow the effects of factors and interaction to be determined.

The most common way to implement an orthogonal multifactor DOE is to use Taguchi tables [10] because results are simple to obtain and the effects of each factor can be better isolated. However, the DOE should be usable in our study case, which means that none of the parameters intervening in the behaviour of the bolted assemblies is allowed to be chaotic. That is why the Taguchi fractional DOE is compared with a complete DOE here. Moreover, this will enable us to highlight the interactions between the parameters, which is not always possible with a multifactor design of experiments.

\section{Experimental Campaign}

To evaluate the behaviour of bolts, an Automatica ${ }^{\circledR}$ test bench [11] was used in the experiments described here. It allows the tightening torque, the preload and the tightening angle to be acquired in real time. The measurement protocol is to tighten the bolt at the maximum speed of Airbus internal standards until the threads of the nut break. Thus, the approach phase of the nut, the linear phase of tensioning the bolt and the non-linear phase of failure can be observed.

This first experimental campaign was limited to EN6115 titanium screws, ASNA aluminium nuts and diameter codes $3(4.76 \mathrm{~mm}), 3 \mathrm{~A}(5.56 \mathrm{~mm})$ and $4(6.35 \mathrm{~mm})$. There 
are three different surface finishes for the screws and three types of nut, so the campaign comprised a total of 27 combinations. Table 2 gives more details on these combinations. In addition, for reasons of repeatability and reliability, 20 tests were carried out per combination, giving a total of 540 tests.

Table 2. Summary table of screw and nut types.

\begin{tabular}{|c|c|c|c|c|c|}
\hline \multicolumn{6}{|c|}{ EN6115 - Screws } \\
\hline \multicolumn{2}{|l|}{ Code } & Material & Surface finish & Lubrication & Diameter range \\
\hline \multicolumn{2}{|l|}{$\mathrm{T}$} & \multirow{3}{*}{$\begin{array}{l}\text { Titanium alloy } \\
6 \mathrm{AL}-4 \mathrm{~V} \\
R_{c} \min =650 \mathrm{MPa}\end{array}$} & $\begin{array}{l}\text { Sulfuric-acid } \\
\text { anodizing }\end{array}$ & \multirow[t]{3}{*}{$\begin{array}{l}\text { Cethyl } \\
\text { alcohol }\end{array}$} & \multirow{3}{*}{$\begin{array}{l}3(4.76 \mathrm{~mm}) \\
3 \mathrm{~A}(5.56 \mathrm{~mm}) \\
4(6.35 \mathrm{~mm})\end{array}$} \\
\hline \multicolumn{2}{|l|}{$\mathrm{V}$} & & $\begin{array}{l}\text { Ion Vapour } \\
\text { Deposition of } \\
\text { aluminium }\end{array}$ & & \\
\hline \multicolumn{2}{|l|}{$\mathrm{K}$} & & $\begin{array}{l}\text { Resin based } \\
\text { Aluminium } \\
\text { coating }\end{array}$ & & \\
\hline \multicolumn{6}{|c|}{ ASNA - Nuts } \\
\hline Code & \multicolumn{2}{|c|}{ Material } & Surface finish & Lubrication & Diameter range \\
\hline 2528 & \multirow{2}{*}{\multicolumn{2}{|c|}{ Aluminium alloy }} & $\begin{array}{l}\text { Anodizing } \\
\text { as per MIL-A-8625 }\end{array}$ & Cethyl alcohol & \multirow{4}{*}{$\begin{array}{l}3(4.76 \mathrm{~mm}) \\
3 \mathrm{~A}(5.56 \mathrm{~mm}) \\
4(6.35 \mathrm{~mm})\end{array}$} \\
\hline 2529 & & & $\begin{array}{l}\text { Anodizing as per } \\
\text { MIL-A- } 8625 \text {, } \\
\text { Type II, class } 2\end{array}$ & & \\
\hline \multirow[t]{2}{*}{2537} & \multicolumn{2}{|c|}{ Nut: Aluminium alloy } & $\begin{array}{l}\text { Anodizing } \\
\text { as per MIL-A-8625 }\end{array}$ & Cethyl alcohol & \\
\hline & \multicolumn{2}{|c|}{$\begin{array}{l}\text { Washer: } \\
\text { Corrosion } \\
\text { Resistance steel }\end{array}$} & Cadmium plating & None & \\
\hline
\end{tabular}

For each combination, an average maximum breaking torque is extracted, which corresponds to the average of the torques for which there is loss of the preload in each repeatability test. Also, using the same principle, the average maximum preload is extracted and, as the torque/preload relationship is known to be very dispersive, the standard deviation of the two previous data is also noted.

\section{Taguchi Factorial Experiment Plan}

A fractional DOE enables the number of trials to be reduced to what is strictly necessary to conclude on the same trends as a complete design of experiments. To respect the experimental campaign, three factors (coating of the screw, type of nut and diameter) at three levels will be used. A Taguchi Table 3 is chosen, and this reduces the campaign to 180 tests, a third of the number needed for the complete experiment plan. 
Table 3. $L_{9}\left(3^{3}\right)$ Taguchi factorial experiment plan.

\begin{tabular}{l|l|l|l}
\hline Tests & Screw surface finish & Type of nut & Diameter \\
\hline 1 & 1 & 1 & 1 \\
\hline 2 & 1 & 2 & 3 \\
\hline 3 & 1 & 3 & 2 \\
\hline 4 & 2 & 1 & 3 \\
\hline 5 & 2 & 2 & 2 \\
\hline 6 & 2 & 3 & 1 \\
\hline 7 & 3 & 1 & 2 \\
\hline 8 & 3 & 2 & 1 \\
\hline 9 & 3 & 3 & 3 \\
\hline
\end{tabular}

The factor columns are balanced and orthogonal. This means that, in each pair of columns, all combinations of factors occur the same number of times. The orthogonal plans will allow us to estimate the effect of each factor on the response, independently of all the other factors. For the moment, no interaction is taken into account even though the type of nut and the coating of the screw could be considered as one, since the coatings of the nuts are not similar and thus can locally modify the coefficient of friction between the thread of the screw and the thread of the nut.

\section{Results}

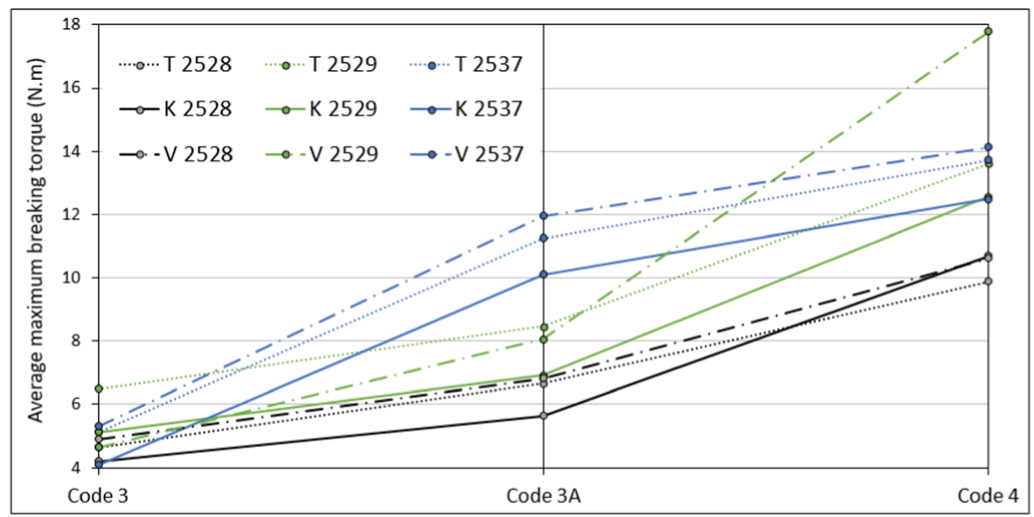

Fig. 1. Average maximum breaking torque for the 27 combinations

The first results that can be extracted are directly linked to the data from the test bench: tightening torque and preload. For example, thanks to the complete plan, the main trends 
in the behaviour of the bolted connection is observable in Fig. 1. The coating of the screw has a small impact on the maximum average breaking torque; a classification is even possible: $\mathrm{V}>\mathrm{T}>\mathrm{K}$. In contrast, the type of nut has a marked influence on the response and the diameter undeniably has an impact that is almost proportional to the tightening torque.

Next, the results of Fig. 2 correspond to the differences between the fractional DOE and the complete design of experiments. To detect this, we use an effect graph corresponding to each factor. There is no difference for the diameter, possibly because of the continuity of this parameter, and the effect of the parameter supports the previous observation. However, there is a big trend difference for the type of nut. It is likely that this comes from the non-linearity of the parameter and the fact that the screw/nut interaction is disregarded. However, when we look at the scale, we see that this effect is globally negligible $(<1.5 \%)$.
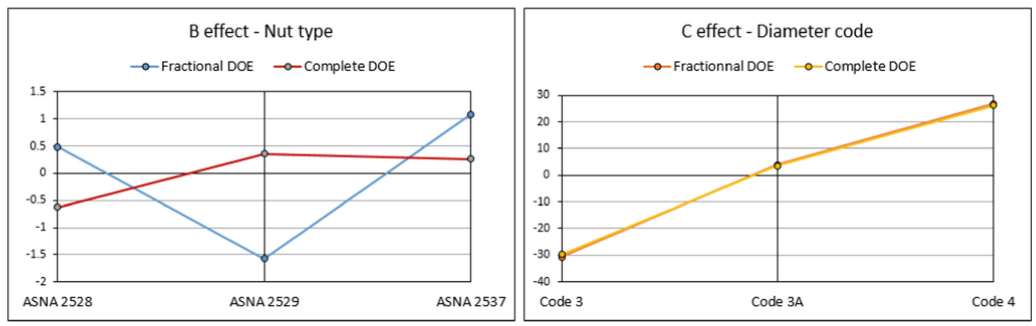

Fig. 2. Differences between fractional and complete DOE on the average maximal preload for the nut and diameter factors expressed in percentages.

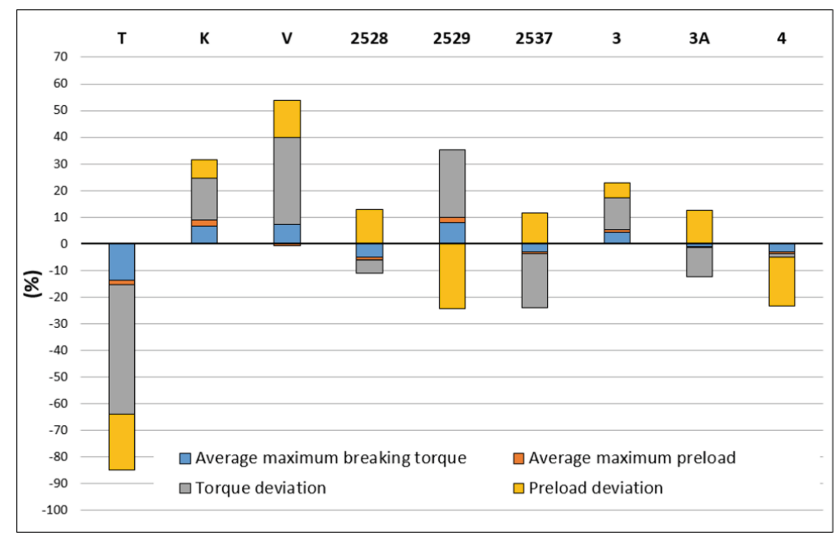

Fig. 3. Differences between multifactor experiments and complete design of experiments expressed in percentage depending on parameters and responses.

Figure 3 summarizes all the differences between the two designs of experiments as a percentage. The average maximum breaking torque and the average maximum preload are rather stable, unlike the standard deviations. This is not surprising: the 
greater the number of tests completed, the greater the dispersion, in particular because of interactions. The most unstable parameters preventing us from using a fractional DOE are the T and V coatings and the ASNA2529 nut. The differences for the coating of screw $\mathrm{T}$ and the diameter code 4 are exclusively negative. In other words, our multifactor experiments are the "worst case" for these factors. Conversely, K and V coatings and diameter code 3 show exclusively positive differences.

\section{Conclusion}

Finally, this study shows us that, on all points, the complexity of the behaviour of a bolted connection does not allow us to approximate it with a fractional design of experiments without taking the interactions of the parameters into account, and these interactions are obtained only through analysis of a complete design of experiments. Now, the complete design of experiments must be analysed in greater depth to highlight predominant points of the behavior of the bolted assemblies. This will allow us to better target our objectives for future experimental campaigns and for future digital models.

\section{References}

1. Benhaddou, T., Chirol, C., Daidie, A., Guillot, J., Pierre, S., Tuery, J.-B.: Pre-tensioning effect on fatigue life of bolted shear joints. Aerosp. Sc. and Techn. 36, 36-43 (2014)

2. Benhaddou, T., Stephan, P., Daidie, A., Alkatan, F., Chirol, C., Tuery, J.-B.: Effect of axial preload on durability of aerospace fastened joints. Int. J. Mech. Sci. 137, 214-223 (2018)

3. Stock, T., Seliger, G.: Opportunities of sustainable manufacturing in industry 4.0. Procedia Cirp. 40, 536-541 (2016)

4. Grzejda, R.: Determination of bolt forces and normal contact pressure between elements in the system with many bolts for its assembly conditions. Adv. Sci. Technol. Res. J. 9(13), 116-121 (2019)

5. Rafik, V. Etude du devissage d'un assemblage aéronautique sous sollicitations transverse. Ph.D. thesis, University of Toulouse (2019)

6. Dols, S. Développement d'une nouvelle méthode de serrage intelligente pour le contrôle des assemblages boulonnés. Ph.D. thesis, University of Toulouse (2016)

7. Goupy, J.: Les plans d'experiences. Rev. MODULAD 34, 74-116 (2006)

8. Box, G., Behnken, D.: Some new three level designs for the study of quantitative variables. Technometrics 2(4), 455-475 (1960)

9. Rechtschaffner, R.L.: Saturated fractions of $2 n$ and 3 factorial designs. Technometrics 9(4), 569-575 (1967)

10. Pillet, M.: Introduction aux Plans d'expériences par la méthode Taguchi. Les Editions d'organisation, Paris (1992)

11. Automaticas. CB2 - automatica (2020). https://www.automatica.info/en/products/testingmachines/tightening-bench-torsion-machine/cb2/ 
Open Access This chapter is licensed under the terms of the Creative Commons Attribution 4.0 International License (http://creativecommons.org/licenses/by/4.0/), which permits use, sharing, adaptation, distribution and reproduction in any medium or format, as long as you give appropriate credit to the original author(s) and the source, provide a link to the Creative Commons license and indicate if changes were made.

The images or other third party material in this chapter are included in the chapter's Creative Commons license, unless indicated otherwise in a credit line to the material. If material is not included in the chapter's Creative Commons license and your intended use is not permitted by statutory regulation or exceeds the permitted use, you will need to obtain permission directly from the copyright holder.

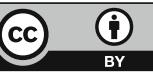

